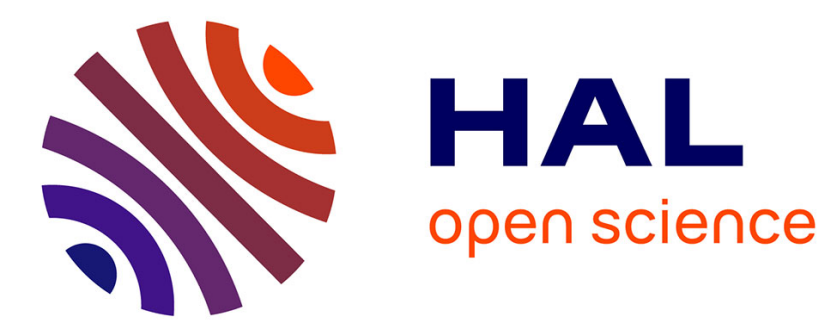

\title{
Defect properties of solar cells with layers of GaP based dilute nitrides grown by molecular beam epitaxy
}

\author{
Artem Baranov, Alexander Gudovskikh, Anton Yu. Egorov, Dmitry
}

Kudryashov, Sylvain Le Gall, Jean-Paul Kleider

\section{- To cite this version:}

Artem Baranov, Alexander Gudovskikh, Anton Yu. Egorov, Dmitry Kudryashov, Sylvain Le Gall, et al. Defect properties of solar cells with layers of GaP based dilute nitrides grown by molecular beam epitaxy. Journal of Applied Physics, 2020, 128 (2), pp.023105. 10.1063/1.5134681 . hal-02946530

\section{HAL Id: hal-02946530 \\ https://hal.science/hal-02946530}

Submitted on 6 Nov 2020

HAL is a multi-disciplinary open access archive for the deposit and dissemination of scientific research documents, whether they are published or not. The documents may come from teaching and research institutions in France or abroad, or from public or private research centers.
L'archive ouverte pluridisciplinaire HAL, est destinée au dépôt et à la diffusion de documents scientifiques de niveau recherche, publiés ou non, émanant des établissements d'enseignement et de recherche français ou étrangers, des laboratoires publics ou privés. 


\section{Defect properties of solar cells with layers of GaP based dilute nitrides grown by molecular beam epitaxy}

Cite as: J. Appl. Phys. 128, 023105 (2020); https://doi.org/10.1063/1.5134681

Submitted: 31 October 2019 . Accepted: 26 June 2020 . Published Online: 14 July 2020

Artem I. Baranov (D), Alexander S. Gudovskikh (D), Anton Yu. Egorov (D), Dmitry A. Kudryashov (D), Sylvain Le Gall (D), and Jean-Paul Kleider (iD)

\section{COLLECTIONS}

Paper published as part of the special topic on Defects in Semiconductors 2020

Note: This paper is part of the Special Topic on Defects in Semiconductors 2020.
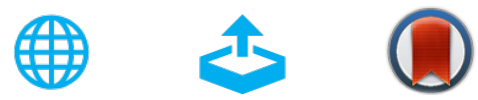

\section{ARTICLES YOU MAY BE INTERESTED IN}

Real-time dynamic evolution monitoring of laser-induced exciton phase flips in 2D hybrid semiconductor $\left(\mathrm{C}_{12} \mathrm{H}_{25} \mathrm{NH}_{3}\right)_{2} \mathrm{PbI}_{4}$

Journal of Applied Physics 128, 023104 (2020); https://doi.org/10.1063/5.0011815

Spoof plasmonic Brewster angle transmission for broadband electromagnetic energy squeezing in the microwave regime

Journal of Applied Physics 128, 023101 (2020); https://doi.org/10.1063/1.5145320

Controlling the direction and intensity of magnetic dipole emission by spoof plasmonic structures

Journal of Applied Physics 128, 023103 (2020); https://doi.org/10.1063/5.0009743

\section{Lock-in Amplifiers up to 600 $\mathrm{MHz}$}
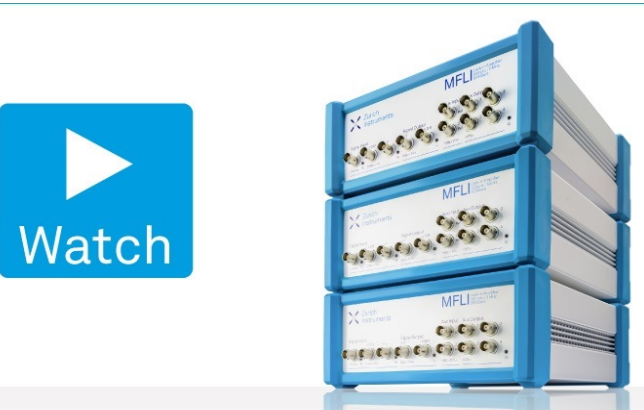


\title{
Defect properties of solar cells with layers of GaP based dilute nitrides grown by molecular beam epitaxy
}

Cite as: J. Appl. Phys. 128, 023105 (2020); doi: 10.1063/1.5134681

Submitted: 31 October 2019 . Accepted: 26 June 2020 .

Published Online: 14 July 2020

Artem I. Baranov, ${ }^{1,2,3,4, a)}$ (D) Alexander S. Gudovskikh, ${ }^{1,2}$ (iD Anton Yu. Egorov, ${ }^{1}$ (D) Dmitry A. Kudryashov, Sylvain Le Gall, ${ }^{3,4}$ (iD) and Jean-Paul Kleider ${ }^{3,4}$ (D)

\author{
AFFILIATIONS \\ ${ }^{1}$ Saint Petersburg National Research Academic University RAS, 194021 Saint Petersburg, Russia \\ ${ }^{2}$ Saint Petersburg Electrotechnical University, 197376 Saint Petersburg, Russia \\ ${ }^{3}$ Université Paris-Saclay, CentraleSupélec, CNRS, Laboratoire de Génie Electrique et Electronique de Paris, 91192 Gif-sur-Yvette, \\ France \\ ${ }^{4}$ Sorbonne Université, CNRS, Laboratoire de Génie Electrique et Electronique de Paris, 75252 Paris, France
}

Note: This paper is part of the Special Topic on Defects in Semiconductors 2020.

${ }^{a}$ Author to whom correspondence should be addressed: baranov_art@spbau.ru

\begin{abstract}
Dilute nitrides lattice-matched to GaP were studied to explore the possibilities to improve their properties by additional indium or arsenic content in the GaPN alloy for further utilization in solar cells. Admittance spectroscopy shows that intrinsic layers of GaPNAs and InP/GaPN grown by molecular-beam epitaxy have unintentional background silicon donor doping. Deep-level transient spectroscopy allowed us to reveal several defect levels. In GaPNAs, two defect levels were detected at $E_{c}-0.58 \mathrm{eV}$ and $E_{v}+0.44 \mathrm{eV}$, with respective concentrations of $4 \times 10^{15} \mathrm{~cm}^{-3}$ and $2 \times 10^{15} \mathrm{~cm}^{-3}$. After thermal annealing, these could be reduced by a factor of two and by more than one order of magnitude, respectively, leading to an increase of external quantum efficiency and open-circuit voltage of solar cells. The InP/GaPN layer exhibits a defect level at $E_{c}-0.44 \mathrm{eV}$ (with a concentration of $2 \times 10^{14} \mathrm{~cm}^{-3}$ ), which is of similar nature as the one at $E_{c}-0.58 \mathrm{eV}$ in GaPNAs. Furthermore, unlike in GaPNAs, defect levels close to midgap were also detected in the InP/GaPN layer. These non-radiative recombination centers lead to poorer photoelectric properties of solar cells based on InP/GaPN as compared to those based on GaPNAs. Therefore, the introduction of arsenic in the compound and post-growth thermal annealing allowed us to reduce the defect concentrations in dilute nitrides and improve photoelectrical properties for photovoltaic applications.
\end{abstract}

Published under license by AIP Publishing. https://doi.org/10.1063/1.5134681

\section{INTRODUCTION}

Nowadays, almost all record values of efficiency are reached for multi-junction solar cells (MJSCs) based on III-V compounds using concentrating lenses. The maximum efficiency of $46 \%$ was obtained in devices fabricated by bonding of two structures grown on different wafers. ${ }^{1}$ However, such a bonding method has issues with cost and high throughput when it comes to terrestrial photovoltaic applications, where monolithic MJSCs, especially MJSCs grown on silicon wafers, should be preferred. According to theoretical simulations $1.1 \mathrm{eV}$ and $1.7 \mathrm{eV}$ are the optimal values of the bandgap energy $\left(E_{g}\right)$ of the bottom and top subcells in a double-junction solar cell. ${ }^{2}$ The first one corresponds to the value of silicon ${ }^{3}$ so it can be used as a wafer, and the top subcell should then be lattice-matched with Si. Possible candidates to this purpose are dilute nitrides based on GaP. GaPN becomes a direct semiconductor when the content of nitrogen exceeds 0.5 at. $\%$ and its bandgap energy drastically decreases. ${ }^{4,5}$ Moreover, the addition of indium and (or) arsenic atoms allows one to vary the bandgap energy of InGaPNAs in a wide range from 1.5 to $2.1 \mathrm{eV}$ while remaining lattice-matched to $\mathrm{Si}$ or $\mathrm{GaP}$ wafers. ${ }^{6}$ Therefore, InGaPNAs $\left(E_{g}=1.7 \mathrm{eV}\right) / \mathrm{Si}$ tandem is considered a promising monolithic double-junction solar cell due to the higher theoretical 
limit of efficiency under AM1.5G (37.4\%) compared to GaInP/ GaAs (35.1\%). ${ }^{6}$ Furthermore, triple-junction solar cells based on the InGaPNAs $(1.8 \mathrm{eV}) / \mathrm{InGaPNAs}(1.4 \mathrm{eV}) / \mathrm{Si}$ structure are preferable to the $\mathrm{GaInP} / \mathrm{GaAs} / \mathrm{Ge}$ structure due to higher potentially achievable efficiency. ${ }^{6}$ For example, we showed that with $10 \mathrm{~ns}$ minority-carrier lifetime in (In) $\mathrm{GaPN}(\mathrm{As})$ a triple-junction solar cell based on the GaPNAs $(2.0 \mathrm{eV}) / \mathrm{GaPNAs}(1.5 \mathrm{eV}) / \mathrm{Si}$ can reach $44.5 \%$ efficiency at a sunlight concentration of 500 suns. ${ }^{7}$

However, so far there are only a few studies of solar cells based on (In) $\mathrm{GaPN}(\mathrm{As})$ lattice-matched to $\mathrm{GaP}$ or $\mathrm{Si}$, and their photovoltaic performance is poor due to insufficient quality of the III-V layers. ${ }^{8-12}$ First of all, the growth of dilute nitrides layers occurs in non-equilibrium conditions at low temperature, which is required for better nitrogen incorporation. Usually, it is less than $500{ }^{\circ} \mathrm{C}$, whereas the optimal growth temperature of $\mathrm{GaAs}$ and $\mathrm{GaP}$ is close to $600^{\circ} \mathrm{C}$. Second, a higher nitrogen content leads to the reduction of the bandgap energy of GaPN but at the same time leads to a degradation of the quality of the material. According to previous studies, the photoluminescence intensity decreases drastically with increasing nitrogen concentration in GaPN; it decreases also in the same layers of dilute nitrides grown on $\mathrm{Si}$ instead of GaP wafers. ${ }^{5,13-15}$ Moreover, the incorporation of nitrogen in the $\mathrm{GaP}$ lattice leads to the appearance of elastic stress in pseudomorphic layers and lattice-mismatch with $\mathrm{GaP}$ and $\mathrm{Si}$ wafers leading to the appearance of dislocations and high concentration of defects (being non-radiative recombination centers) during the growth. Consequently, it can negatively impact the lifetime of charge carriers, the electron and hole mobility and other electrical properties that are crucial for optoelectronic devices. Nevertheless, there are only few studies concerned with defects in the InGaPNAs alloys isoperiodic to $\mathrm{GaP}$ and Si. The method of optically detected magnetic resonance has been used to find and describe a number of defects of the $\mathrm{Ga}_{i}$ type in $\mathrm{GaPN}$ (As) layers, ${ }^{16-18}$ but this method does not allow one to obtain useful information on their concentration, energy position, and capture cross sections. These parameters are necessary for computer simulation of the solar cell performance and to evaluate the influence of these defects on the lifetime of charge carriers in dilute nitrides. Deep-level transient spectroscopy
(DLTS) has been used to study defects only in GaP:N layers [with a nitrogen concentration of $\left.(3-8) \times 10^{18} \mathrm{~cm}^{-3}\right]^{19-24}$ and $\mathrm{GaP}_{0.991} \mathrm{~N}_{0.009}$, ${ }^{25}$ but similar studies of InGaPNAs with higher nitrogen content have not been found in literature.

On the other hand, different ways were also proposed to improve the quality of GaP-based dilute nitrides, for example, rapid thermal annealing leads to the inhibition of some defects in $\mathrm{GaPN},{ }^{26}$ and reduction of defect concentration was detected after annealing in GaPNAs layers by admittance spectroscopy (AS) in our previous work. ${ }^{27}$ Also, additional incorporation of arsenic and indium leads to the significant enhancement of the PL amplitude, ${ }^{14}$ and the inhibition of defect formation in dilute nitrides. ${ }^{18,28,29}$ However, the quality of (In) GaPN(As) lattice-matched to GaP has still remained poor and solar cells based on these alloys suffer from the low carrier lifetimes.

The main goal of this work is to explore defects in GaP-based dilute nitrides using capacitance techniques and to describe their influence on the photoelectrical properties of $\mathrm{p}-\mathrm{i}-\mathrm{n}$ single-junction solar cell structures, that are preferred to $\mathrm{p}-\mathrm{n}$ junction structures for dilute nitrides having low carrier lifetimes. ${ }^{30,31}$ We present data on defects detected in (In) GaPN(As) layers grown by MBE on GaP wafers, in relation with the alloy content. We focus on the $\mathrm{i}$-GaPNAs quaternary alloy and on $\mathrm{i}-\mathrm{InGaPN}$ grown as a submonolayer digital alloy (SDA) ${ }^{32-34}$ of InP/GaPN. Indeed, the latter method was successfully applied to the growth of defect-free InGaAsN (900 nm thick) as InAs/GaAsN in our previous work. ${ }^{35}$ The photovoltaic structures are investigated by various capacitive techniques such as capacitance-voltage measurements $(C-V)$, admittance spectroscopy (AS) and DLTS. These experiments provide information on the formation of defects in these compounds during the growth process. Furthermore, the influence of thermal annealing on the solar cell properties is also explored.

\section{EXPERIMENTS AND METHODS}

Three types of single-junction solar cells based on $\mathrm{p}-\mathrm{i}-\mathrm{n}$ heterostructures were grown by $\mathrm{MBE}$ using a Veeco Gen III equipment with an RF-plasma source of nitrogen on $n-G a P ~(100)$ wafers
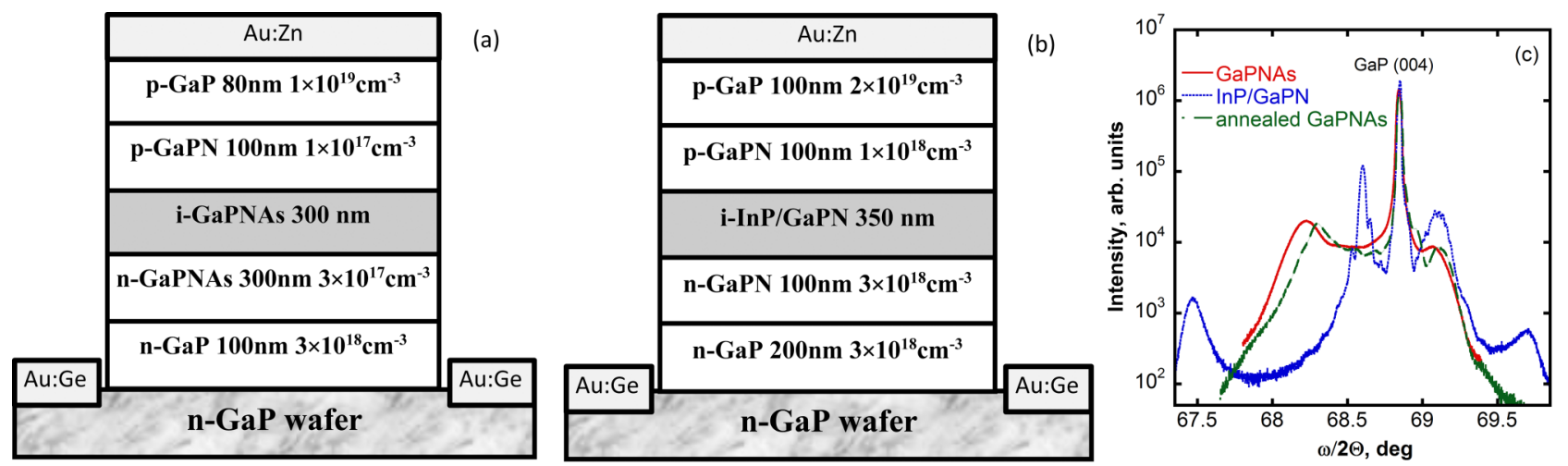

FIG. 1. Schematic view of the $p-i-n$ structures with $\mathrm{i}-\mathrm{GaPNAs}$ (a) and $\mathrm{i}-\mathrm{InP} / \mathrm{GaPN}$ (b) active layers. X-ray rocking curves measured in the vicinity of GaP(004) reflection for $\mathrm{GaPNAs}$ and InP/GaPN structures. 
$\left(5 \times 10^{17} \mathrm{~cm}^{-3}\right)$. The first one is based on a $\mathrm{p}-\mathrm{i}-\mathrm{n}$ structure with an undoped $300 \mathrm{~nm}$ thick GaPNAs layer confined between two symmetric p- and n-type GaPNAs layers and also with a $100 \mathrm{~nm}$ thick front $\mathrm{p}-\mathrm{GaP}$ layer as a wide bandgap window, as described in Fig. 1(a). The second one has the same structure, but it was thermally annealed in the MBE chamber at higher temperature in phosphorous flow. In these two samples, the arsenic content varies in the range of $15 \%-30 \%$ in the quaternary GaPNAs alloy for better nitrogen incorporation since it was necessary to reduce the bandgap down to $1.7 \mathrm{eV}$. The third one is a $\mathrm{p}-\mathrm{i}-\mathrm{n}$ structure with $350 \mathrm{~nm}$ thick undoped InGaPN $\left(\mathrm{E}_{\mathrm{g}}=2.04 \mathrm{eV}\right)$ grown as InP/GaPN $(0.3 \mathrm{~nm} / 10 \mathrm{~nm})$ SDA confined between $\mathrm{p}$ - and n-type GaPN layers, and with a $100 \mathrm{~nm}$ thick front $\mathrm{p}-\mathrm{GaP}$ layer as a wide bandgap [see Fig. 1(b)]. Silicon and beryllium were used for doping of the n- and p-layers in the structures, respectively.

Structural and optical properties of the epitaxial GaPNAs layers grown by MBE were described in detail in Ref. 14, and, since the focus of the current paper is on electronic properties, we just briefly show some $\mathrm{x}$-ray diffraction data that prove the structural quality of the grown structures. X-ray diffraction measurements were carried out near the (004) GaP reflection using PANalytical $X$ 'PertPro diffractometer in parallel $\mathrm{x}$-ray beam geometry. The $\mathrm{x}$-ray rocking curves measured in the vicinity of the $\mathrm{GaP}(004)$ reflection of the samples are presented in Fig. 1(c). Second order satellite peaks are observed, which indicates high structural quality of the structures based on GaPAsN layer and InP/GaPN superlattice. For the latter, the value of the superlattice period is maintained with acceptable accuracy. The presence of interference oscillations near the zero peak of the superlattice indicates a high crystalline quality of the epitaxial layers. Scanning electron microscopy (not shown here) also demonstrates smooth surface and homogeneous structures of the grown samples.

All samples were grown without any antireflection coating. The post-growth method including photolithography, vacuum evaporation of metals, and precise wet etching of $\mathrm{GaP}$ rich alloys ${ }^{36}$

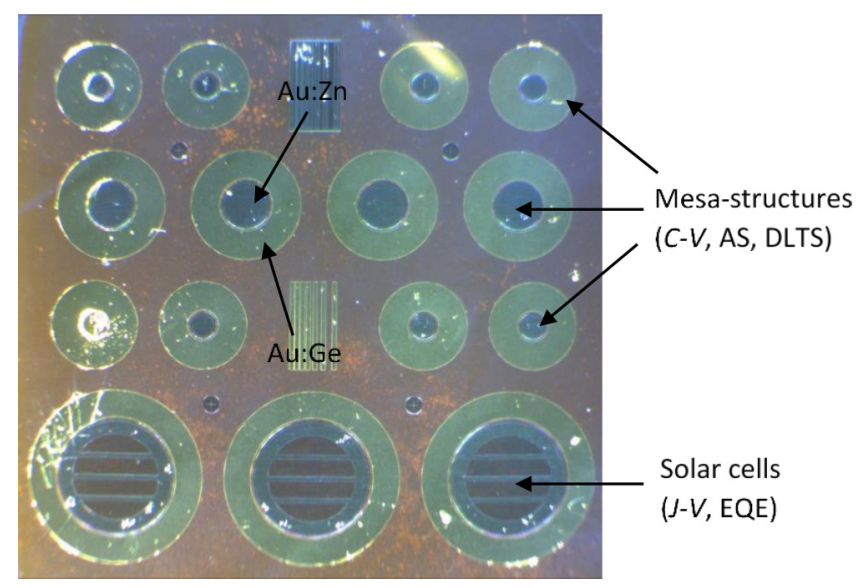

FIG. 2. Photograph of a fabricated sample with mesa-structures and solar cells used in various experiments. was applied for the fabrication of mesa-structures and solar cells ${ }^{37}$ illustrated in Fig. 2. Au:Ge and Au:Zn alloys were used for the $\mathrm{n}-\mathrm{GaP}$ wafer and for the $\mathrm{p}-\mathrm{GaP}$ top contact, respectively. The ohmic behavior of the current-voltage characteristics for contacts was reached after rapid thermal annealing using a JIPelec JetFirst 100 equipment. For photoelectric measurements, we used a grid top contact, while simple circular dots with diameters of 0.5 and $1 \mathrm{~mm}$ were used for capacitance measurements.

Current-voltage characteristics were measured at $25^{\circ} \mathrm{C}$ using a Keithley 2400 source-meter under AM1.5G illumination provided by a SunLiteTM Solar Simulator from ABET Technologies. The external quantum efficiency (EQE) was measured in the range of $300-800 \mathrm{~nm}$ using a homemade installation. Various space charge capacitance methods were used to analyze the electronic properties of the active i-layers of GaP-based dilute nitrides. First, the $C-V$ characteristics were measured to define the level of doping in the layers at a frequency of $1 \mathrm{MHz}$. Admittance spectroscopy was performed to study the defect properties (activation energy $E_{a}$ and capture cross section $\sigma$ ) in the layers of dilute nitrides ${ }^{38}$ using a precision E7-20 RLC-meter in the frequency range from $20 \mathrm{~Hz}$ to $1 \mathrm{MHz}$ and with a test voltage amplitude of $50 \mathrm{mV}$. The classical capacitance DLTS ${ }^{39}$ method was performed to get more information about the detected deep defects using a Boonton-7200 capacitance bridge at a frequency of $1 \mathrm{MHz}$ and with a test voltage amplitude of $100 \mathrm{mV}$. All capacitance measurements were performed in a Janis VPF-100 liquid nitrogen vacuum cryostat in the temperature range from 77 to $360 \mathrm{~K}$. AFORS-HET 2.5 software $^{40}$ was used for numerical simulations of solar cells. It allows one to calculate the capacitance and photoelectrical characteristics of the solar cell in the one-dimensional case. ${ }^{41}$

\section{RESULTS}

\section{A. Quasi steady-state capacitance measurements}

Here, we partially repeat measurements of admittance spectroscopy for samples with i-GaPNAs, which also were studied in a previous work. ${ }^{27}$ The improvement of post-growth technology for mesa-structure fabrication and the optimization of ohmic contacts allow us to measure the capacitance in a more precise and reliable way and to clarify uncertainties in the analysis of experimental data. The admittance spectroscopy is based on the measurement of the capacitance and conductance of the junction using a small signal alternating voltage at different frequencies and at various temperatures. Figure 3 shows the temperature dependence of the capacitance at different frequencies, $C(T, f)$, and at zero DC bias, for samples with GaPNAs [Fig. 3(a)] and InP/GaPN i-layers [Fig. 3(b)]. The steps observed in the capacitance curve with increasing temperature evidence the response of a defect level in the bulk, or at the interface, or the presence of a potential barrier in the (In) $\mathrm{GaPN}(\mathrm{As}) / \mathrm{GaP}$ heterojunction. An analysis of theoretical band diagrams and the experimental current-voltage characteristics without S-shape suggests that the features observed in the admittance spectroscopy are not associated with parasitic potential barriers at interfaces. Measurements of $C(T, f)$ at different bias voltages demonstrated that the peak and step positions are independent of the applied bias voltage, which evidence the response of defect levels in the bulk of the material, rather than at the interface. 

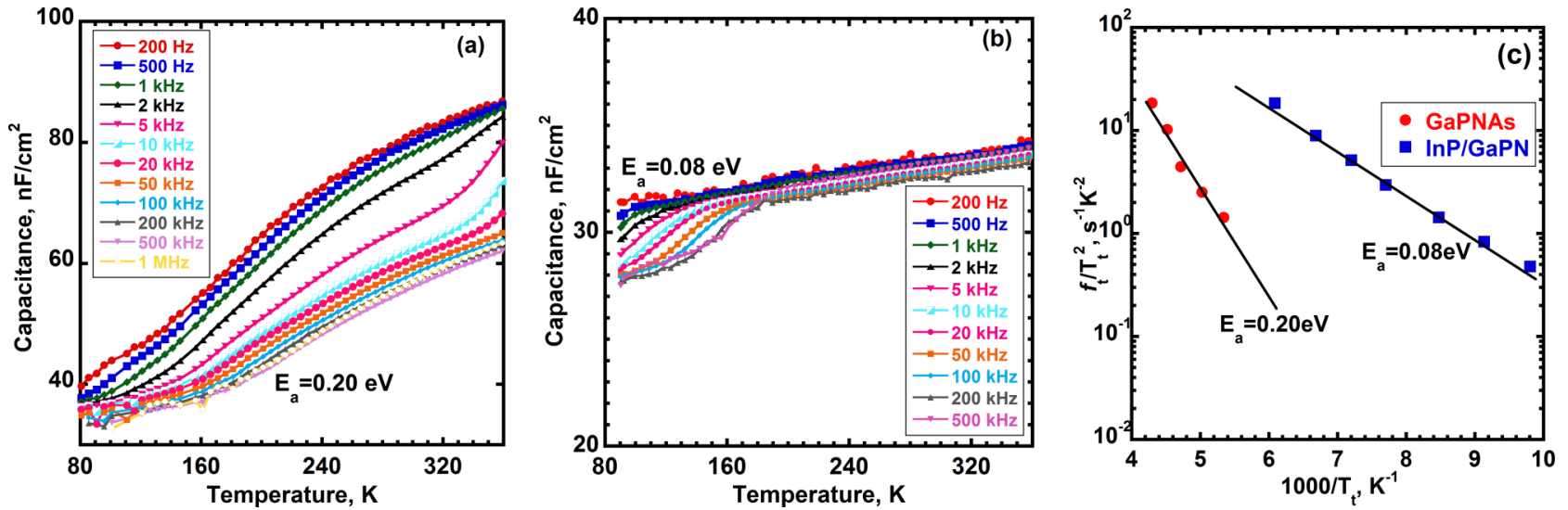

FIG. 3. Experimental temperature dependence of the capacitance at various frequencies for samples of GaPNAs (a) and InP/GaPN (b). Corresponding Arrhenius plots of $f_{t} / T_{t}^{2}, f_{t}$ and $T_{t}$ being the frequency and temperature, respectively, at the turn-on of defect response (c).

A more detailed description of the admittance spectroscopy technique for $\mathrm{p}-\mathrm{i}-\mathrm{n}$ junctions is given in our previous work where fully depleted InGaAsN layers were explored. ${ }^{35}$ To estimate parameters of a defect level, the following relation is used:

$$
\frac{f_{t}}{T_{t}^{2}}=\frac{v_{300} N_{300} \sigma}{\pi(300)^{2}} \exp \left(-\frac{E_{a}}{k_{B} T_{t}}\right),
$$

where $f_{t}$ is the turn-on frequency, $T_{t}$ is the turn-on temperature, $k_{B}$ is the Boltzmann constant, $E_{a}$ is an activation energy, $v_{300}$ and $N_{300}$ are the thermal velocity and effective density in the band at $300 \mathrm{~K}$, respectively, and $\sigma$ is the capture cross section of the defect for the majority carriers. ${ }^{38}$ The turn-on position is determined at a given frequency in a capacitance vs temperature plot, by the maximum of the capacitance derivative $\mathrm{dC} / \mathrm{d} T$. The capacitance of the sample with GaPNAs [Fig. 3(a)] exhibits a low temperature step overlapping with another high temperature response. According to the Arrhenius plots of $f_{t} / T_{t}^{2}$, the parameters extracted from the low temperature step are $E_{a}=0.20 \mathrm{eV}$ and $\sigma=1.7 \times 10^{-15} \mathrm{~cm}^{2}$ [Fig. 3(c)]. Previously, we suggested that it is a unique defect for undoped i-GaPNAs. But now, according to the parameters of the low-temperature defect in our $\mathrm{n}-\mathrm{GaPNAs}^{27}$ and parameters of similar defects in other studies, ${ }^{19,21,22}$ it can be suggested that this detected defect corresponds to the T1 level. This defect is a $\mathrm{Si}_{\mathrm{Ga}}+\mathrm{V}_{\mathrm{P}}$ complex appearing under non-equilibrium growth conditions when a large number of gallium and phosphorus vacancies are formed and Si occupies left gallium sites. Therefore, the i-layer of GaPNAs has a similar response as $\mathrm{n}-\mathrm{GaPNAs}$ doped by $\mathrm{Si}$ but the step amplitude is extremely lower. It means that this defect has a significantly lower concentration, but its existence can be associated with unintentional background doping of i-GaPNAs by silicon during the growth process. On the other hand, parameters for the defect responding at higher temperature could not be estimated. This is due to the overlap of its response with the preceding one at low frequencies, while at high frequencies (higher than $5 \mathrm{kHz}$ ), the limited temperature range $(\mathrm{T}<360 \mathrm{~K})$ of our equipment does not allow us to observe the capacitance step that should occur at higher temperature

Capacitance curves of the sample with i-InP/GaPN exhibit low temperature series of blurred steps and then monotonous growth of capacitance without any feature [Fig. 3(b)]. According to the Arrhenius plot [Fig. 3(c)], these steps correspond to a response with a thermal activation energy $E_{a}=0.08 \mathrm{eV}$ and a capture cross section $\sigma=1.45 \times 10^{-16} \mathrm{~cm}^{2}$. Possibly, this defect could be a donortype point defect formed by silicon atoms at the site of gallium in the $\mathrm{GaP}$ lattice $\left(\mathrm{Si}_{\mathrm{Ga}}\right)$ at a position of $E_{C}-0.085 \mathrm{eV}$. This defect was also observed in undoped GaP:N layers grown by vapor phase epitaxy. ${ }^{23}$ At temperatures above $160 \mathrm{~K}$, the capacitance is almost independent of the frequency and slowly increases with heating up to $360 \mathrm{~K}$, so there is no response from defect levels in the explored temperature range. Therefore, admittance spectroscopy allowed us to detect defects with low activation energy that can be associated with silicon incorporation in dilute nitrides and can be responsible for unintentional doping of these layers. However, their low values of $E_{a}$ and $\sigma$ indicate that they should not be considered efficient centers of non-radiative recombination in InGaPNAs.

Since admittance spectroscopy did not reveal contributions from defect levels at high frequency and at low temperature [Fig. 3], $C-V$ curves were measured in the reverse bias voltage from 0 to $-3 \mathrm{~V}$ for $1 \mathrm{MHz}$ at $80 \mathrm{~K}$ [Fig. 4(a)]. Obviously, the capacitance decreases vs reverse voltage in different ways in the two samples: the i-GaPNAs sample has the strongest dependence of capacitance on bias voltage, while the InP/GaPN sample exhibits almost no capacitance change. The estimated dependence of the width $\left(d_{\text {eff }}=\epsilon / C\right.$, where $\epsilon$ being the dielectric permittivity) of the space charge region (SCR) on applied reverse voltage is shown in Fig. 4(b).

In an ideal $\mathrm{p}-\mathrm{i}-\mathrm{n}$ structure, where the doping concentration in $\mathrm{p}$ - and n-layers is high and the i-layer is undoped, the width of the space charge region almost corresponds to the thickness of the i-layer and is independent of the DC applied voltage. This is observed in the $\mathrm{i}-\mathrm{InP} / \mathrm{GaPN}$ sample, with an effective width 

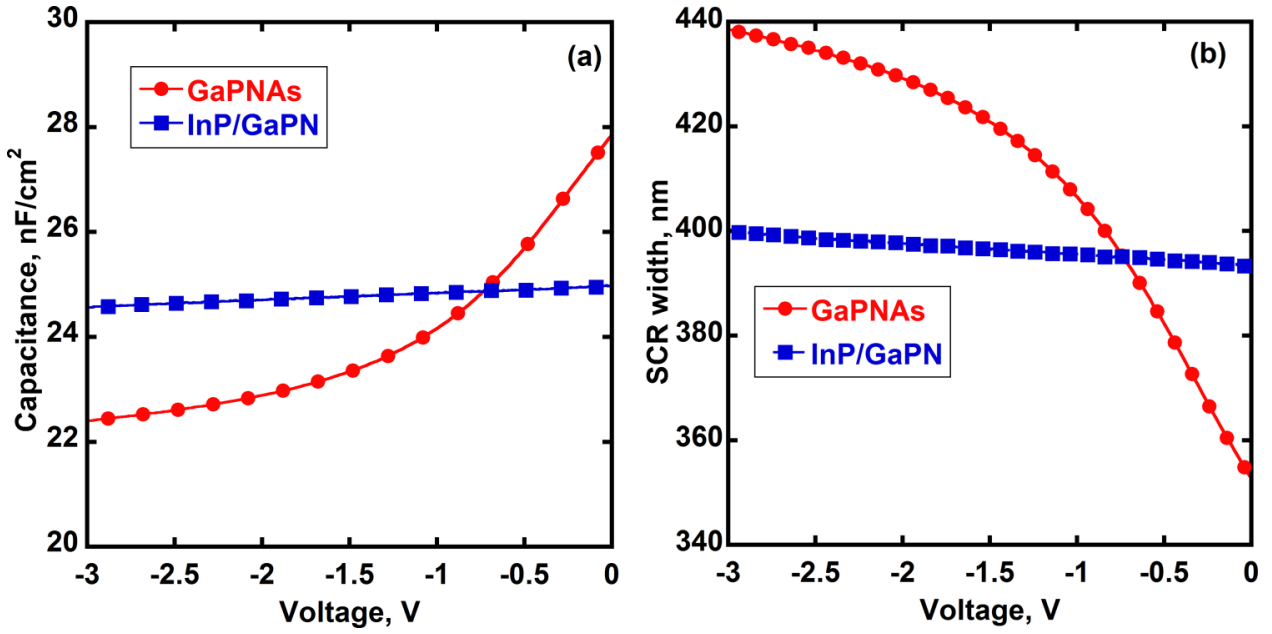

FIG. 4. Capacitance-voltage characteristics (a) and space charge region width-voltage dependences (b) for the GaPNAs and InP/GaPN samples. Data were taken at measurement temperature and frequency of $80 \mathrm{~K}$ at $1 \mathrm{MHz}$, respectively.

extracted from the capacitance of about $390 \mathrm{~nm}$, close to the value of $350 \mathrm{~nm}$ estimated from the growth process; the discrepancy can come from the unknown value of the relative dielectric permittivity in dilute nitrides (we use the value of $\mathrm{GaP}$ of 11.1) or/and from an error in the estimation of the active device area.

On the contrary, the GaPNAs sample exhibits a voltage dependence of the capacitance similar to that of a classical $p-n$ junction. Therefore, we can assume that an unintentional doping of the GaPNAs layer takes place during the growth. In addition, the presence of silicon related defects in the i-layers suggests that the background doping in the studied sample should be of n-type.

In order to estimate the background doping concentration in both (i) GaPNAs and InP/GaPN layers, numerical simulations were performed. The doping concentration in the adjacent layers was fixed to the values estimated from the growth recipe: $3 \times 10^{18} \mathrm{~cm}^{-3}$ and $1 \times 10^{18} \mathrm{~cm}^{-3}$ for the $\mathrm{n}$ - and p-layer, respectively, of the InP/GaPN sample, and $3 \times 10^{17} \mathrm{~cm}^{-3}$ and $1 \times 10^{17} \mathrm{~cm}^{-3}$ for the GaPNAs sample. Only the unintentional donor concentration in the i-layer was varied. The simulated $C-V$ characteristics are shown in Fig. 4, and they are compared to the experimental ones (black dots). For the GaPNAs structures, a perfect fit is obtained for a donor concentration of $3 \times 10^{16} \mathrm{~cm}^{-3}$ [Fig. 5(a)]. For the InP/ GaPN sample, the background doping concentration should be lower than $1 \times 10^{16} \mathrm{~cm}^{-3}$ [Fig. 5(b)]. Consequently, GaPNAs seems to be more unintentionally donor doped than InP/GaPN for the used growth processes. This leads to a more parabolic shape of the band diagram in the GaPNAs layer, as compared to a more linearlike one in the InP/GaPN layer (see insets).

\section{B. DLTS measurements}

The samples were studied by the deep-level transient spectroscopy (DLTS) ${ }^{39}$ technique to explore defects with higher activation energy in the i-layer of the dilute nitrides. It is a transient method that is based on the measurement of the junction capacitance vs time following a change in applied voltage. The difference in
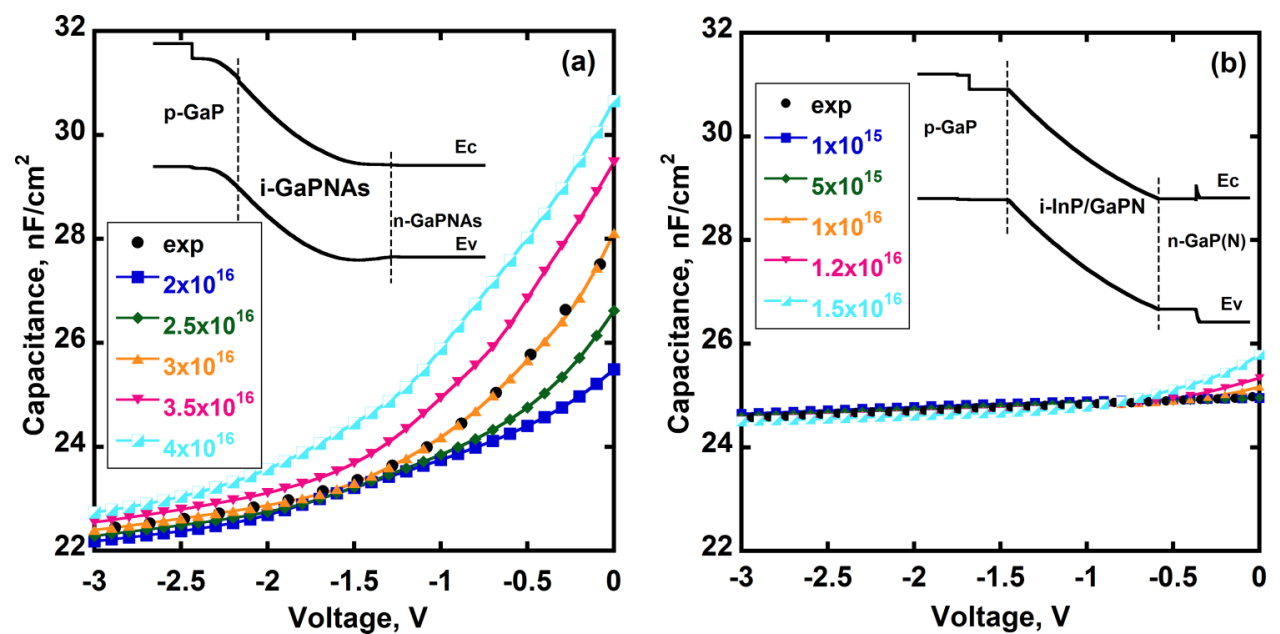

FIG. 5. Simulated capacitance-voltage characteristics of samples performed at $80 \mathrm{~K}$ for various concentrations (in $\mathrm{cm}^{-3}$ ) of unintentional $n$-type doping in the $i$-layer (various symbols on colored lines) of GaPNAs (a) and InP/GaPN (b), compared to experimental data (black dots). Calculated equilibrium band diagrams of the structures with i-GaPNAs (with unintentional n-type doping of $3 \times 10^{16} \mathrm{~cm}^{-3}$ ) and $\mathrm{i}-\mathrm{InP} /$ GaPN (with unintentional n-type doping of $\mathrm{n}=1 \times 10^{16} \mathrm{~cm}^{-3}$ ) are shown in the insets. 
capacitance at two different times $t_{1}$ and $t_{2}$ after switching the voltage is recorded as a function of temperature, $T$, and defined as the spectral function $S(T)$. In the presence of a defect level in the bandgap, $S(T)$ exhibits a maximum at $T_{\max }$, and parameters of the defect can be estimated by following equations:

$$
\begin{gathered}
\left(T_{\text {max }}\right)=\sigma v_{t h} N e^{\frac{-E_{a}}{k_{B} T_{\text {max }}}}, \\
e\left(T_{\text {max }}\right)=\frac{\ln \left(t_{2} / t_{1}\right)}{t_{2}-t_{1}},
\end{gathered}
$$

where $N$ is the effective density in the band and $e$ is the emission frequency defined by the rate window. The DLTS spectrum $S(T)$ of the GaPNAs sample was obtained for different rate windows under the following conditions: initial reverse bias voltage $V_{\text {init }}=-2 \mathrm{~V}$, filling pulse amplitude $V_{\text {pulse }}=+1.5 \mathrm{~V}$, and duration of the filling pulse $t_{\text {pulse }}=100 \mathrm{~ms}$ [Fig. 6(a)]. It exhibits two clear series of peaks associated with responses from majority-carrier traps (here, a positive value of the peak corresponds to the response from majority-carrier traps). The first series is located in the temperature range $80-120 \mathrm{~K}$, and it corresponds to a defect level with an activation energy $E_{a}=0.18 \mathrm{eV}$ and a capture cross section $\sigma=3.1 \times 10^{-15} \mathrm{~cm}^{2}$, as estimated from the Arrhenius plot in Fig. 6(e). These values correlate well with parameters of the defect detected by admittance spectroscopy above. Another clear series of peaks is detected in the temperature range of $200-280 \mathrm{~K}$, and it corresponds to a deep defect with parameters of $E_{a}=0.58 \mathrm{eV}$ and $\sigma=6.9 \times 10^{-13} \mathrm{~cm}^{2}$. As noted above, grown i-layers are unintentionally $n$-type doped so the majority-carrier traps are electron traps, and their energy position is given by $E_{t}=E_{c}-E_{a}$.

Defect concentrations were estimated at $2 \times 10^{15} \mathrm{~cm}^{-3}$ and $4 \times 10^{15} \mathrm{~cm}^{-3}$ for defects at $E_{c}-0.18 \mathrm{eV}$ and $E_{c}-0.58 \mathrm{eV}$, respectively, in the case of $\mathrm{p}-\mathrm{n}$ junctions ${ }^{42}$ under the condition of $N_{D}=3 \times 10^{16} \mathrm{~cm}^{-3}$ from the $C-V$ measurements. For the latter, we could also estimate the capture time which is of the order of $10^{-11} \mathrm{~s}$ assuming a thermal velocity value of $10^{7} \mathrm{~cm} / \mathrm{s}$. This is a very small value meaning that the detected defect level can be considered an effective center of non-radiative recombination in GaPNAs. As we will see later, this can explain the low external quantum efficiency (EQE) in solar cells based on a GaPNAs absorber (see Discussion below). Consequently, its concentration
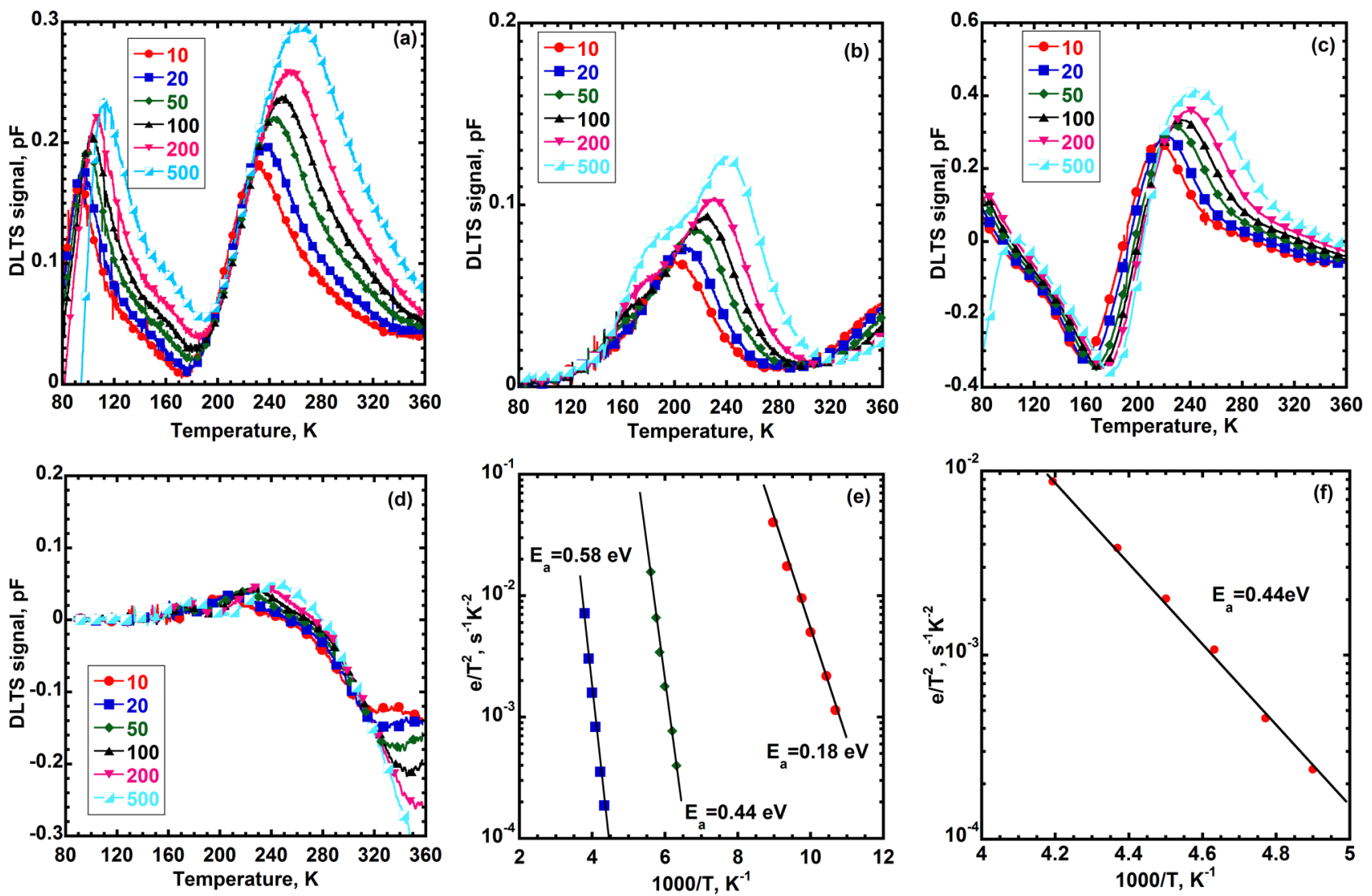

FIG. 6. DLTS spectra $S(T)$ for GaPNAs [(a) and (c)] and InP/GaPN [(b) and (d)] samples for different rate windows (in s $\left.{ }^{-1}\right)$. Two electrical injection conditions are applied: (a) and (b) initial reverse bias $\left(V_{\text {init }}=-2 \mathrm{~V} ; V_{\text {pulse }}=+1.5 \mathrm{~V} ; t_{\text {pulse }}=100 \mathrm{~ms}\right)$ and (c) and (d) initial forward bias $\left(V_{\text {init }}=+0.2 \mathrm{~V} ; V_{\text {pulse }}=+0.8 \mathrm{~V} ; t_{\text {pulse }}=50 \mathrm{~ms}\right)$. Arrhenius plots of the detected peaks for the GaPNAs and InP/GaPN samples are shown in (e) and (f), respectively. 
should be decreased in future work since lifetimes in dilute nitrides must be larger than $10^{-9} \mathrm{~s}$ in order to reach good multijunction solar cell performance. ${ }^{7}$

The DLTS technique also allows one to detect minority-carrier traps. To this purpose, a forward bias voltage must be applied during the filling pulse. Therefore, a DLTS spectrum $S(T)$ for the GaPNAs sample was also measured under the following conditions: initial forward applied bias voltage $V_{\text {init }}=+0.2 \mathrm{~V}$, filling pulse amplitude $V_{\text {pulse }}=+0.8 \mathrm{~V}$, and duration of the filling pulse $t_{\text {pulse }}=50 \mathrm{~ms}$ [Fig. 6(c)]. A significant difference between spectra $S(T)$ in Figs. 6(a) and $6(\mathrm{c})$ is observed at temperatures below $200 \mathrm{~K}$. $S(T)$ starts to decrease from $80 \mathrm{~K}$ and presents a series of negative peaks shifting with the rate window in the temperature range of $160-180 \mathrm{~K}$. This indicates a response from a minority-carrier trap level that can mask the response from the defect at $E_{c}-0.18 \mathrm{eV}$ in the range of 80 $120 \mathrm{~K}$ due to a higher concentration. Parameters of this defect level are estimated from the Arrhenius plot [Fig. 6(e)]: $E_{a}=0.44 \mathrm{eV}$, which corresponds to a level position of $E_{v}+0.44 \mathrm{eV}$ since holes are the minority carriers, and $\sigma=2.6 \times 10^{-11} \mathrm{~cm}^{2}$. The defect concentration is estimated at $2 \times 10^{15} \mathrm{~cm}^{-3}$. This defect can also be considered an effective center of non-radiative recombination. Furthermore, for both experiments, $S(T)$ decreases at temperatures above $240 \mathrm{~K}$ up to the measurement limit of $360 \mathrm{~K}$ for all rate windows. This evidences the absence of other responses from minority- and majority-carrier traps, suggesting that there are no defects with higher activation energy in the considered GaPNAs layer.

In the InP/GaPN sample, the DLTS spectra obtained under the conditions $V_{\text {init }}=-2 \mathrm{~V}, V_{\text {pulse }}=+1.5 \mathrm{~V}$, and $t_{\text {pulse }}=100 \mathrm{~ms}$ exhibit positive peaks in the temperature range of $200-260 \mathrm{~K}$ corresponding to the response from a majority-carrier trap level [Fig. 6(b)]. According to the Arrhenius plot in Fig. 6(f), these peaks correspond to the response from a defect level with an activation energy $E_{a}=0.44 \mathrm{eV}$, a capture cross section $\sigma=1.7 \times 10^{14} \mathrm{~cm}^{2}$ and a concentration $N_{T}=2 \times 10^{14} \mathrm{~cm}^{-3}$. Unlike the GaPNAs sample, $S(T)$ starts to increase again at temperatures above 280 $300 \mathrm{~K}$ up to the limit temperature of the used setup $(360 \mathrm{~K})$. This suggests the existence of another majority-carrier trap, but measurements up to $420 \mathrm{~K}$ in another setup also did not allow us to obtain the level parameters due to a monotonous DLTS signal increase and the absence of maximum in broad $S(T)$ spectra even for low emission rates at high temperature. Therefore, this can be attributed to the response from a broadened defect level with large activation energy. A similar response was observed earlier for unintentionally doped layers of GaP:N ${ }^{43}$ where it was associated with the EL2 defect typical for GaAs. ${ }^{44}$ Future experiments could be focused on the modification of the setup in order to be able to heat the sample up to $600 \mathrm{~K}$ for a correct estimation of defect parameters. The lack of response from the defect detected by admittance spectroscopy is explained by the low value of activation energy $E_{a}=0.08 \mathrm{eV}$, since its peak on DLTS spectra should be at temperatures below $80 \mathrm{~K}$.

DLTS spectra were also measured under minority-carrier injection conditions for the InP/GaPN sample [Fig. 6(d)]: $V_{\text {init }}=+0.2 \mathrm{~V}, V_{\text {pulse }}=+0.8 \mathrm{~V}$, and $t_{\text {pulse }}=50 \mathrm{~ms}$. As a result, the $S$ (T) spectra remain almost the same at temperatures below $160 \mathrm{~K}$, but at a higher temperature, they strongly decrease due to the contribution of a minority-carrier trap. The estimation of its parameters is impossible since the peaks are not observed in the used temperature range. Thus, according to the experiments, there are deep traps with high activation energy for both holes and electrons in the InP/GaPN layer, but the precise estimation of their parameters is impossible due to overlapping of their responses and to the limited available temperature range. A similar behavior was observed for deep defects in InGaAsN layers. ${ }^{45}$

\section{Discussion}

\section{Nature of defects}

Here, the nature of detected defects at $E_{c}-0.44 \mathrm{eV}$ in $\mathrm{InP} /$ $\mathrm{GaPN}$ and $E_{c}-0.58 \mathrm{eV}$ in GaPNAs is considered. A defect with similar parameters as in InP/GaPN was observed earlier in the $\mathrm{GaPN}^{25}$ and GaP:N ${ }^{19-21}$ layers grown on GaP wafers. This defect was a majority-carrier trap in similar $n$-type layers in these works so it indirectly can suggest the presence of background doping of $n$-type in our i-InP/GaPN layer. Previously, the possible structure of this defect was proposed as a complex based on a pair of nitrogen atoms at the phosphorus sites $\left(\mathrm{N}_{\mathrm{P}}-\mathrm{N}_{\mathrm{P}}\right)$ and the vacancy of gallium $\mathrm{V}_{\mathrm{Ga}}$, arising as a result of displacement of gallium due to the incorporation of nitrogen in the $\mathrm{GaP}$ lattice. Responses from the defect at $E_{c}-0.58 \mathrm{eV}$ in GaPNAs were observed in the similar temperature region and the extracted parameter values suggest a correlation between this defect and the defect at $E_{c}-0.44 \mathrm{eV}$ in $\mathrm{InP} / \mathrm{GaPN}$. One possible explanation is that the latter transforms into the former due to additional arsenic content in the alloy.

Moreover, the peaks on $S(T)$ spectra associated with both defects are broadened and their peak value increases with the rate window. It suggests a non-exponential behavior of responses from the defect levels due to different possible reasons, one being the response from extended ${ }^{46}$ defects rather than from point defects. A useful method to distinguish between point ${ }^{47,48}$ and extended ${ }^{49}$ defects is the measurement of the dependence of the peak amplitude on the duration of filling pulse at fixed temperatures: the key distinction is that the peak amplitude should not saturate in case of extended defects while it should saturate for point defects. For both defects, at $E_{c}-0.44 \mathrm{eV}$ in $\mathrm{InP} / \mathrm{GaPN}$ and $E_{c}-0.58 \mathrm{eV}$ in GaPNAs, the peak value increases with increasing filling pulse duration from $1 \mathrm{~ms}$ to $100 \mathrm{~ms}$, but the peak value saturates for filling pulse duration longer than $50 \mathrm{~ms}$ [Fig. 7]. Consequently, it suggests that point defects based on $\mathrm{N}_{\mathrm{P}}-\mathrm{N}_{\mathrm{P}}$ and $\mathrm{V}_{\mathrm{Ga}}$ with $E_{a}=0.44 \mathrm{eV}$ can transform into defects with some broader energy distribution in compounds of dilute nitrides (In)GaPN(As). The most probable reason for the non-exponential behavior in the considered materials originates from alloying. ${ }^{50}$ Probably, in the case of dilute nitrides, a strong fluctuation in the composition occurs due to non-equilibrium growth conditions and to the tendency of nitrogen clusterization that leads to the transformation of point defects into extended ones with broadened energy distribution. Furthermore, high arsenic content of $15 \%-30 \%$ can also lead to some energy distribution for the defect level in GaPNAs. Therefore, the estimated values of capture cross section and activation energy should be considered "average" parameters for the detected defect levels.

In summary, in the i-GaPNAs layer DLTS allowed to detect responses from defect levels at $E_{c}-0.18 \mathrm{eV}$ (that is also detected by admittance spectroscopy), $E_{c}-0.58 \mathrm{eV}$, and $E_{v}+0.44 \mathrm{eV}$. On the 

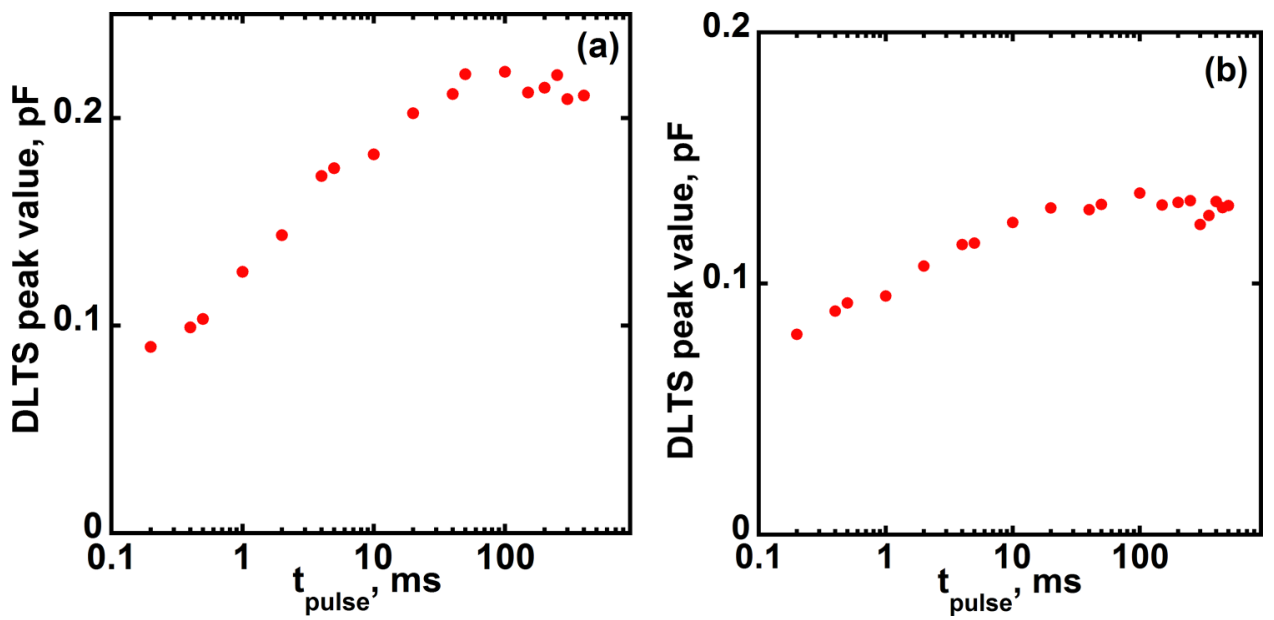

FIG. 7. Dependence of the DLTS peak amplitude as a function of the filling pulse duration $t_{\text {pulse }}$ for the defects at $E_{c}-0.58 \mathrm{eV}$ in GaPNAs (a) and at $E_{c}-0.44 \mathrm{eV}$ in $\mathrm{InP} / \mathrm{GaPN}(\mathrm{b})$, for a rate window of $50 \mathrm{~s}^{-1}$. other hand, the $\mathrm{i}-\mathrm{InP} / \mathrm{GaPN}$ layer exhibits the defect level at $E_{c}-0.44 \mathrm{eV}$, which has a similar nature as the one at $E_{c}-0.58 \mathrm{eV}$ in i-GaPNAs, but we also detected additional deep-level traps near the middle of the bandgap that can be considered centers of nonradiative recombination, which are not observed in i-GaPNAs in the explored temperature range.

\section{Correlation with photoelectric properties and improvements after annealing}

The current density-voltage $(J-V)$ characteristics measured under AM1.5G illumination and the external quantum efficiency (EQE) of the solar cells based on GaPNAs and InP/GaPN absorbers are presented in Figs. 8(a) and 8(b), respectively. Small values of the fill factor for these $J-V$ curves are explained primarily by large ohmic losses related to imperfect upper contact grid. The GaPNAs solar cell has a short-circuit current density $J_{S C}=3.93 \mathrm{~mA} / \mathrm{cm}^{2}$ and open-circuit voltage $V_{O C}=0.87 \mathrm{~V}$, while the
InP/GaPN one exhibits a higher open-circuit voltage of $1.24 \mathrm{~V}$ due to higher bandgap energy of $2.04 \mathrm{eV}$, but much lower short-circuit current. This is also confirmed by the spectral response: the GaPNAs sample has higher peak (35\%) and integral EQE values than the InP/GaPN sample. This is related to lower lifetime of charge carriers in the InP/GaPN material compared to GaPNAs, and it is correlated with the existence of higher defect concentrations observed above by the capacitance techniques. It confirms the conclusion suggested by other authors ${ }^{13}$ about a better compensation of elastic stresses by arsenic than by indium. Nitrogen is a $\mathrm{V}$-group element so it tries to take place in the sublattice of $\mathrm{V}$-group atoms in the GaP lattice (phosphorus sites). Arsenic is also a V-group element so it also stands in phosphorus sites and it leads to more effective stress compensation than indium incorporation since the latter is a III-group element. Additionally, it is possible to distinguish two peaks in the EQE curve for all samples. This can be explained by the peculiar structure of the conduction band in InGaPNAs dilute nitrides where two conduction subbands may
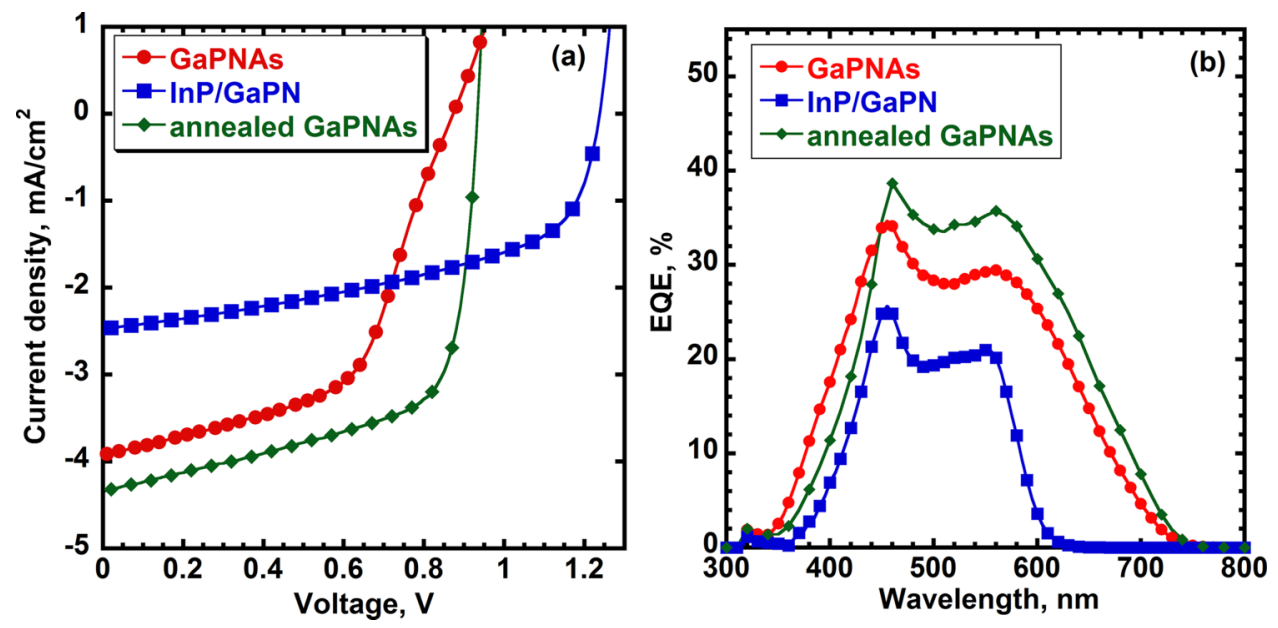

FIG. 8. Current density-voltage characteristic under AM1.5G (a) and external quantum efficiency (b) of samples. 

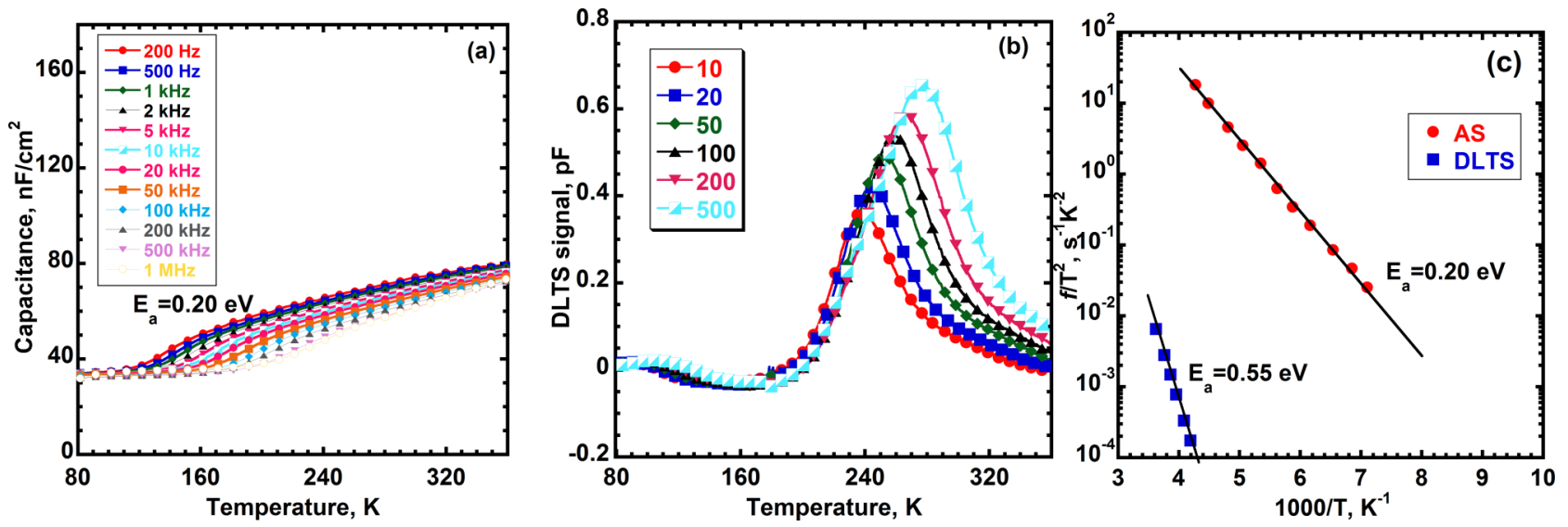

FIG. 9. Experimental admittance spectroscopy and DLTS results for the GaPNAs sample after annealing: (a) dependence of the capacitance upon temperature at various frequencies, (b) DLTS spectra $S(T)$ measured under injection conditions of $V_{\text {init }}=+0.2 \mathrm{~V}, V_{\text {pulse }}=+0.5 \mathrm{~V}$, and $t_{\text {pulse }}=50 \mathrm{~ms}$ for different rate windows (in $\mathrm{s}^{-1}$ ), and (c) Arrhenius plot for detected defects.

exist. The detailed investigation of this phenomenon is described in our previous work. ${ }^{30}$ Therefore, GaPNAs shows better photoelectrical properties than InP/GaPN due to smaller defect concentrations.

Since it is well known that thermal annealing can have positive influence on the performance of solar cells through reduction of recombination centers and improvements in contact properties, the GaPNAs sample were annealed at $570-650^{\circ} \mathrm{C}$ for $3 \mathrm{~min}$ at phosphorous flow in the MBE chamber.

Results of admittance spectroscopy after annealing are presented in Fig. 9(a). The $C(T)$ dependence is similar to that of the as-grown sample in Fig. 3(a): the same response from the defect level with $E_{a}=0.20 \mathrm{eV}$ and possible responses from deep defects in the high temperature range. However, according to the $C-V$ curve at $80 \mathrm{~K}$ (not presented here), i-GaPNAs has lower free carrier concentrations $\left(1 \times 10^{16} \mathrm{~cm}^{-3}\right)$ after thermal annealing, and the i-layer can be considered fully depleted and the sample as an almost ideal " $\mathrm{p}-\mathrm{i}-\mathrm{n}$ " junction. Therefore, we modified the voltage conditions in the DLTS experiment in order to be able to fill traps inside the i-layer and detect their responses. The DLTS spectra $S(T)$ were measured for different rate windows under the following conditions: initial applied bias voltage $V_{\text {init }}=+0.2 \mathrm{~V}$, injection filling pulse amplitude $V_{\text {pulse }}=+0.5 \mathrm{~V}$, and duration of the injection filling pulse $t_{\text {pulse }}=50 \mathrm{~ms}$ [Fig. 9(b)]. The $S(T)$ spectra exhibit a series of peaks in the same temperature range of $240-280 \mathrm{~K}$ as for the as-grown sample [Fig. 6(a)] with a similar activation energy of $E_{a} \approx 0.55 \mathrm{eV}$ as estimated from the Arrhenius plot in Fig. 9(c), thus revealing the same defect. However, the defect concentration was estimated at $2 \times 10^{15} \mathrm{~cm}^{-3}$, which has been reduced by a factor of two compared to the as-grown sample. Obviously, there is also a response in the temperature range of $120-170 \mathrm{~K}$ associated with minority-carrier traps, but their peaks on $S(T)$ are broadened with a very small amplitude so it is impossible to reliably estimate the parameters of these defects. Nevertheless, their response is much lower compared to that in the as-grown sample, indicating that their concentration is definitely lower.
The lower concentration of both majority- and minoritycarrier traps detected in annealed samples leads to better photovoltaic performance [Fig. 8]. First of all, the short-circuit current increases and reaches a value of $4.34 \mathrm{~mA} / \mathrm{cm}^{2}$ due to significant improvement in the EQE spectrum. Furthermore, $V_{o c}$ and $F F$ increase up to $0.93 \mathrm{~V}$ and $65 \%$, respectively. Therefore, the annealed GaPNAs sample has the best photovoltaic properties among the studied samples due to smaller defect concentration in the i-layer. Nevertheless, its EQE is still low $(<40 \%)$, but it should be noted that the studied structures are not provided with antireflection coatings. However, even with allowance for the reflection losses (in the range of $20 \%-40 \%$ ), the values of quantum efficiency obtained in the $\mathrm{p}-\mathrm{i}-\mathrm{n}$ structure are yet not sufficient to provide sufficient photovoltaic performance in the top junction of MJSCs. In order to further improve the efficiency, it is necessary to increase the thickness and, hence, the level of absorption in the undoped absorber region. In the same time, further studies should be focused on the modification of growth processes to reduce the formation of defects that will be even more harmful in thicker absorbing layers.

\section{CONCLUSION}

Dilute nitrides lattice-matched to $\mathrm{GaP}$ were studied to explore the possibilities to improve their properties by additional content of indium or arsenic in the alloy to compensate elastic stresses in GaPN. Admittance spectroscopy and DLTS methods allowed us to detect deep levels in the i-layer of GaPNAs and InP/GaPN grown by MBE. GaPNAs exhibit responses from defect levels at $E_{c}-0.18 \mathrm{eV}, E_{c}-0.58 \mathrm{eV}$, and $E_{v}+0.44 \mathrm{eV}$. The concentration of the latter was strongly reduced after thermal annealing, and the concentration of the defect level at $E_{c}-0.58 \mathrm{eV}$ was also slightly reduced. This led to better photovoltaic performance of annealed samples since both defects affect the charge carrier lifetime in dilute nitrides. The $\mathrm{InP} / \mathrm{GaPN}$ layer exhibits a defect level at 
$E_{c}-0.44 \mathrm{eV}$, which has a similar nature as the one at $E_{c}-0.58 \mathrm{eV}$ in i-GaPNAs. Furthermore, the existence of deep levels close to midgap was revealed in the InP/GaPN layer, while they were not observed in i-GaPNAs layers. This leads to poorer photoelectric properties of solar cells using i-InP/GaPN absorber layers compared to that using i-GaPNAs layers. Therefore, using arsenic in GaPNAs and subsequent post-growth thermal annealing is better suited for photovoltaic applications, but deep defect concentrations still need to be reduced in order to achieve very high conversion efficiencies.

\section{ACKNOWLEDGMENTS}

The study of samples with superlattice InP/GaPN was supported by the Russian Scientific Foundation under Grant No. 17-19-01482. The study of samples with GaPNAs layers was supported by the grant from the President of Russian Federation (No. CП-1207.2019.1) awarded to Artem I. Baranov.

\section{DATA AVAILABILITY}

The data that support the findings of this study are available from the corresponding author upon reasonable request.

\section{REFERENCES}

${ }^{1}$ F. Dimroth, T. N. D. Tibbits, M. Niemeyer, F. Predan, P. Beutel, C. Karcher, E. Oliva, G. Siefer, D. Lackner, P. Fus-Kailuweit, A. W. Bett, R. Krause, C. Drazek, E. Guiot, J. Wasselin, A. Tauzin, and T. Signamarcheix, IEEE J. Photovoltaics 6, 343 (2016).

${ }^{2}$ F. Meillaud, A. Shah, C. Droz, E. Vallat-Sauvain and C. Miazza, Sol. Energy Mater. Sol. Cells 90, 2952 (2006).

${ }^{3}$ S. Adachi, Properties of Group-IV, III-V and II-VI Semiconductors (John Wiley \& Sons, Ltd, Chichester, 2005).

${ }^{4}$ C. Skierbiszewski, P. Perlin, P. Wisniewski, W. Knap, T. Suski, W. Walukiewicz, W. Shan, K. M. Yu, J. W. Ager, E. E. Haller, J. F. Geisz, and J. M. Olson, Appl. Phys. Lett. 76, 2409 (2000).

5I. A. Buyanova, G. Yu. Rudko, W. M. Chen, H. P. Xin, and C. W. Tu, Appl. Phys. Lett. 80, 1740 (2002).

${ }^{6}$ J. F. Geisz and D. J. Friedman, Semicond. Sci. Technol. 17, 769 (2002).

${ }^{7}$ D. A. Kudryashov, A. S. Gudovskikh, E. V. Nikitina, and A. Yu. Egorov, Semiconductors 48, 381 (2014).

${ }^{8}$ J. F. Geisz, D. J. Friedman, and S. Kurtz, in Twenty-Ninth IEEE Photovoltaic Specialists Conference 2002 (IEEE, 2002), pp. 864-867.

9J. F. Geisz, J. M. Olson, D. J. Friedman, K. M. Jones, R. C. Reedy, and M. J. Romero, in Proceedings of the 31st IEEE PVSC (IEEE, 2005), pp. 695-698.

${ }^{10}$ S. Sukrittanon, R. Liu, Y. G. Ro, J. L. Pan, K. L. Jungjohann, C. W. Tu, and S. A. Dayeh, Appl. Phys. Lett. 107, 153901 (2015).

${ }^{1}$ S. Almosni, P. Rale, C. Cornet, M. Perrin, L. Lombez, A. Létoublon, K. Tavernier, C. Levallois, T. Rohel, N. Bertru, J. F. Guillemoles, and O. Durand, Sol. Energy Mater. Sol. Cells 147, 53 (2016).

${ }^{12}$ K. Yamane, M. Goto, K. Takahashi, K. Sato, H. Sekiguchi, H. Okada, and A. Wakahara, Appl. Phys. Express 10, 075504 (2017).

${ }^{13}$ A. A. Lazarenko, E. V. Nikitina, E. V. Pirogov, M. S. Sobolev, and A. Yu. Egorov, Semiconductors 48, 392 (2014).

${ }^{14}$ A. A. Lazarenko, E. V. Nikitina, M. S. Sobolev, E. V. Pirogov, D. V. Denisov, and A. Yu. Egorov, Semiconductors 49, 479 (2015).

${ }^{15} \mathrm{~S}$. Almosni, C. Robert, T. Nguyen Thanh, C. Cornet, A. Létoublon, T. Quinci, C. Levallois, M. Perrin, J. Kuyyalil, L. Pedesseau, A. Balocchi, P. Barate, J. Even, J. M. Jancu, N. Bertru, X. Marie, O. Durand, and A. Le Corre, J. Appl. Phys. 113, 123509 (2013).
${ }^{16}$ N. Q. Thinh, I. P. Vorona, I. A. Buyanova, W. M. Chen, S. Limpijumnong, S. B. Zhang, Y. G. Hong, H. P. Xin, C. W. Tu, A. Utsumi, Y. Furukawa, S. Moon, A. Wakahara, and H. Yonezu, Phys. Rev. B 71, 125209 (2005).

${ }^{17}$ D. Dagnelund, I. A. Buyanova, X. J. Wang, W. M. Chen, A. Utsumi, Y. Furukawa, A. Wakahara, and H. Yonezu, J. Appl. Phys. 103, 063519 (2008).

${ }^{18}$ D. Dagnelund, J. Stehr, A. Y. Egorov, W. M. Chen, and I. A. Buyanova, Appl. Phys. Lett. 102, 021910 (2013).

${ }^{19}$ B. Tell and F. P. J. Kuijpers, J. Appl. Phys. 49, 5938 (1978).

${ }^{20}$ G. Ferenczi, P. Krispin, and M. Somogyi, J. Appl. Phys. 54, 3902 (1983).

${ }^{21}$ P. Kamiński, W. Strupiński, and K. Roszkiewicz, J. Cryst. Growth 108, 699 (1991).

${ }^{22}$ A. V. Skazochkin, Y. K. Krutogolov, and Y. I. Kunakin, Semicond. Sci. Technol. 10, 634 (1995).

${ }^{23}$ A. V. Skazochkin, Y. K. Krutogolov, and G. G. Bondarenko, Semicond. Sci. Technol. 11, 495 (1996).

${ }^{24}$ K. Ždánský, J. Zavadil, D. Nohavica, and S. Kugler, J. Appl. Phys. 83, 7678 (1998).

${ }^{25}$ A. F. Basile, S. Hatakenaka, H. Okada, and A. Wakahara, J. Vac. Sci. Technol. A 27, 531 (2009)

${ }^{26}$ D. Dagnelund, C. W. Tu, A. Polimeni, M. Capizzi, W. M. Chen, and I. A. Buyanova, Phys. Status Solidi C 10, 561 (2013).

${ }^{\mathbf{2 7}}$ A. I. Baranov, A. S. Gudovskikh, K. S. Zelentsov, E. V. Nikitina, and A. Yu. Egorov, Semiconductors 49, 524 (2015).

${ }^{28}$ O. I. Rumyantsev, P. N. Brunkov, E. V. Pirogov, and A. Yu. Egorov, Semiconductors 44, 893 (2010).

${ }^{29}$ A. I. Baranov, J. P. Kleider, A. S. Gudovskikh, A. Darga, E. V. Nikitina, and A. Yu. Egorov, J. Phys. Conf. Ser. 741, 012077 (2016)

${ }^{30}$ A. I. Baranov, A. S. Gudovskikh, E. V. Nikitina, and A. Yu. Egorov, Tech. Phys. Lett. 39, 1117 (2013).

${ }^{31}$ N. Miyashita, N. Ahsan, and Y. Okada, Prog. Photovoltaics Res. Appl. 24, 28 (2016).

${ }^{32}$ M. Sato and Y. Horikoshi, J. Appl. Phys. 66, 851 (1989).

${ }^{33}$ R. Cingolani, O. Brandt, L. Tapfer, G. Scamarcio, G. C. La Rocca, and K. Ploog, Phys. Rev. B 42, 3209 (1990).

${ }^{34}$ A. Y. Egorov, A. E. Zhukov, P. S. Kop'ev, N. N. Ledentsov, M. V. Maksimov, and V. M. Ustinov, Fiz. Tekh. Poluprovodn. 28, 604 (1994). [Semiconductors 28, 363 (1994)].

${ }^{35}$ A. I. Baranov, A. S. Gudovskikh, D. A. Kudryashov, A. A. Lazarenko, I. A. Morozov, A. M. Mozharov, E. V. Nikitina, E. V. Pirogov, M. S. Sobolev, K. S. Zelentsov, A. Yu. Egorov, A. Darga, S. Le Gall, and J.-P. Kleider, J. Appl. Phys. 123, 161418 (2018).

${ }^{36}$ D. A. Kudryashov, A. S. Gudovskikh, and A. I. Baranov, Semiconductors 52, 1775 (2018).

${ }^{37}$ A. I. Baranov, A. S. Gudovskikh, D. A. Kudryashov, I. A. Morozov, A. M. Mozharov, and K. S. Zelentsov, J. Phys. Conf. Ser. 1124, 041034 (2018).

${ }^{38}$ D. L. Losee, J. Appl. Phys. 46, 2204 (1975).

${ }^{39}$ D. V. Lang, J. Appl. Phys. 45, 3023 (1974).

${ }^{40}$ W. G. J. H. M. Van Sark, L. Korte, and F. Roca, Physics and Technology of Amorphous-Crystalline Heterostructure Silicon Solar Cells (Springer, Berlin, 2012).

${ }^{41}$ R. Varache, C. Leendertz, M. E. Gueunier-Farret, J. Haschke, D. Muñoz, and L. Korte, Sol. Energy Mater. Sol. Cells 141, 14 (2015).

${ }^{42}$ Y. Zohta and M. O. Watanabe, J. Appl. Phys. 53, 1809 (1982)

${ }^{43}$ M. Matyas, Jr., Phys. Status Solidi A 97, 297 (1986).

${ }^{44}$ J. Dabrowski and M. Schemer, Phys. Rev. B 40, 10391 (1989).

${ }^{45}$ S. W. Johnston, R. Ahenkiel, A. Ptak, D. Friedman, and S. Kurtz, in National Center for Photovoltaics and Solar Program Review Meeting, Denver, CO, 24-26 March 2003 (NREL, 2003), p. NREL/CP-520-33557 1.

${ }^{46}$ W. Schröter, J. Kronewitz, U. Gnauert, F. Riedel, and M. Seibt, Phys. Rev. B 52, 13726 (1995).

${ }^{47}$ D. Pons, J. Appl. Phys. 55, 3644 (1984).

${ }^{48}$ E. PŁaczek-Popko, J. Trzmiel, E. Zielony, S. Grzanka, R. Czernecki, and T. Suski, Physica B 404, 4889 (2009).

${ }^{49}$ T. Wosiński, J. Appl. Phys. 65, 1566 (1989).

${ }^{50}$ P. Omling, L. Samuelson, and H. G. Grimmeiss, J. Appl. Phys. 54, 5117 (1983). 